\title{
What did we know and which questions did we ask with regard to environmental contaminants in the early 1970s?
}

\author{
This article belongs to Ambio's 50th Anniversary Collection. Theme: Environmental \\ contaminants
}

Arne Jernelöv

Published online: 19 January 2021

In the field of environmental contaminants three Ambio articles are highlighted as important corner stones in building the understanding of the field that we have today. The first is Sören Jensen's article about the discovery of PCBs (1972), the second is a state of the art summary of the transport of organochlorine compounds to the Arctic by Wania and Mackay (1993), and the third is the article by Mergler et al. (2007) who give a comprehensive update on the knowledge at the time about methylmercury exposure and health effects in humans. In separate articles in this issue, Wania (2021) and Mergler (2021) have given their hindsight perspectives of their articles. In Jensen's case (2021) his views are presented in the form of an interview, where I asked the questions and he provided the answers, as his vision problems make writing difficult.

The importance of these contributions become obvious when one considers the knowledge we had and the questions we asked at the time. In 1972 it was ten years since Rachel Carson published "Silent Spring", a book that had enormous influence over the way we viewed agricultural biocides in general and chlorinated insecticides in particular (Carson 1962). Arguably, Rachel Carson did not only write a bestselling popular science book, she also did what researchers should have done: combine results and information from different branches of biology and chemistry. Science, obviously, was at the time too compartmentalized to do it, so it took a journalist and science writer to see the big picture. The main conclusions today appear simple and obvious: When you spread out biocides that do not degrade rapidly, other organisms in addition to those you target may be adversely affected and even more so as many of these substances tend to bioaccumulate, i.e. increase in concentration the higher up in the food chain they get. Rachel Carson wrote mostly about chlorinated insecticides like DDT, aldrin, dieldrin and their effects on birds. DDT was already a familiar substance and although she in " $\mathrm{Si}$ lent Spring" pointed out that several other chlorinated insecticides were both more toxic and persistent, the subsequent debate mostly circled around just DDT. Given the prominence in the debate, it is no surprise that DDT was intensively studied. Two major metabolites were identified: DDE and DDD, both more persistent than their parent chemical. Environmental samples from all over the globe were analyzed, mostly with gas-liquid chromatography, and especially DDE peaks were found both in samples from practically everywhere including polar regions and those from deep oceans. It seemed hard to believe that a compound mostly used in tropical and temperate regions would get that far in measurable quantities in a relatively short time.

Two of three papers selected for this celebration of important Ambio articles in the field of environmental contaminants relate to this problem area. Sören Jensen identified PCBs as environmental contaminants (Jensen 1972). For some time by then, mysterious peaks in the electron capture gas chromatograms had been noted. They were often classified as impurities in the solvents or carrier gas and seen as a hindrance in the analysis of agricultural pesticides. One of them overlapped with DDE, which meant that it either got undetected or overestimated dependent on how the chemist dealt with the interpretation problem. Some of the reports of high concentrations of DDE, often presented as "total DDT" at an early state after introduction of the insecticide and in odd places were in fact one of the PCBs, that had been around much longer and in totally different usages.

Even when PCBs had been identified and could be separated the distribution pattern of DDT, and its more persistent metabolite DDE, had a poor match with the places of application. The presence in coastal marine 
organisms was first explained as caused by runoff from agricultural areas and river input to the sea, but Ed Goldberg among others pointed out that the high concentrations in the marine environment off southern California could not be explained that way, and he suggested an evaporation and atmospheric fall-out process which he called "global distillation" (Goldberg 1975). Robert Riseborough-in finding that the evaporation/fall-out process with DDE in terrestrial environments could happen over and over again - talked about "grasshopper jumps". It was also likened to "ping-pong balls bouncing on a hard surface with some soft patches were many balls would come to rest" seeing cold and acid areas as the soft patches. Rappe (1974) described the Arctic in relation to moderately volatile chlorinated hydrocarbons as following "the rule of the cold wall". Gradually a deeper understanding of the phenomena developed and in the Ambio article Global fractionation and cold condensation of low volatility organochlorine compounds Wania and Mackay (1993) gave the state of the art.

The story of mercury as an environmental contaminant can be said to have started in the 1950s. In Japan the Minamata disease struck, first thought to have been a nerve infection but later identified as methylmercury poisoning. In Sweden, dead birds of prey and seed-eaters like pheasants (Phasianus colchicus) and yellowhammers (Emberiza citrinella) were found to contain high levels of mercury and Karl Borg identified the seed-dressing agent methylmercury as the cause (Borg 1966). That put the initial focus on environmental mercury research on the methylated form. From earlier toxicological studies mostly in the occupational health field it was also known that alkyl mercury compounds and methylmercury in particular were the most toxic to humans as they pass both the blood-brain barrier and the placenta barrier. The human body would degrade all tested organomercurials but at different rates and methylmercury was the one with the longest half-life and also therefore seen as the most harmful. When methylmercury had finally and conclusively been identified as the cause of Minamata disease (Hachiya 2006), transferred to humans by fish and shellfish, the question came up if methylmercury used in agriculture could find its way to water courses and fish and back to humans. Neutron activation analysis of total mercury quickly revealed relatively high concentrations in fish in Sweden, especially in predatory ones like pike (Esox lucius). The more global interest in environmental mercury rose when a Norwegian student in Canada, Norvald Fimreite, found high levels of mercury in fish in the Great Lakes (Fimreite 1970).

To understand how things unfolded it helps to look at the analytical possibilities at the time. Total mercury was mostly analyzed with a colorimetric method that used dithizone. It was not very sensitive and would mistake e.g. copper and cadmium for mercury. The far better alternative was neutron activation, if you had a nuclear reactor at hand. In Stockholm we had one, now almost forgotten, in the rock below the Royal Institute of Technology. Torbjörn Westermark adopted it for mercury analysis. In the 1950s the methods for methylmercury analysis were insensitive, but with [the development of the] electron capture detector and Gage extraction, methylmercury chloride could be measured in low concentrations. Thus, in the mid-1960s we had a good, but hard to get by and expensive, method to analyze total mercury and a good inexpensive one to analyze methylmercury.

The further studies of Alf Johnels, Torbjörn Westermark and colleagues (Johnels et al. 1967) showed that concentrations of mercury in their standardized one kilogram pike, contrary to expectations, were lower in water courses in agricultural areas than in many forested ones. The mystery thickened when Gunnel Westöö found that practically all mercury in fish, regardless of from where it came, was in the form of methylmercury (Westöö and Norén 1967). The explanation came when Sören Jensen and Arne Jernelöv discovered that microorganisms present in lake sediment could convert inorganic mercury to mono- and di-methyl mercury (Jensen and Jernelöv 1967, 1969). Many toxicologists initially doubted the findings, arguing that organisms would not invest energy to produce highly toxic compounds with no benefit to the producer. The experiments, however, could easily be reproduced and the results were confirmed over and over again and thus gradually accepted.

Later two biochemical mechanisms for the conversion were identified. John Wood and coworkers found the $\mathrm{B}_{12}$ itself and bacteria that produce it can methylate mercury (Wood et al. 1968). Lars Landner showed that an erroneous synthesis of methionine in the presence of mercury, may occur in all methionine producing organisms, resulting in methylation of mercury instead of sulfur in homocysteine (Landner 1971). Thus, methylation of mercury does not take place in man and other mammalians and birds, for whom methionine is an essential amino acid, and for whom methylmercury's ability to pass the blood/brain and placenta barriers lead to especially high intoxication risks. A high capacity for (di)methylmercury formation in sulfate reducing marine bacteria was also found and a third biochemical pathway postulated.

As the toxicological focus was on methylmercury and as a reliable analytical method was more readily available for it than for total mercury, a large number of methylmercury analysis were performed and the environmental mercury discussion centered around this compound. Then came flameless atomic absorption spectroscopy, a highly specific 
and sensitive method for total mercury analysis, and a growing interest in global circulation of mercury and the main focus shifted. A number of toxicological questions with regard to methylmercury that were identified already during the Minamata disaster remained and more were added during the Iraq mercury catastrophe, when imported green revolution wheat was imported from Mexico and methylmercury dressed to protect it from fungal attacks and then not only planted but also eaten by humans and domestic animals.

Studies of populations at the Seychelles (Myers et al. 2003) and Faroe islands (Grandjean et al 1997) gave conflicting results as to the toxicological effects of relative low level exposure from eating methylmercury containing marine organisms. The Ambio article "Methylmercury Exposure and Health Effects in Humans" by Mergler et al. (2007) summarizes the knowledge.

Naturally, we have learned a lot when it comes to the risk that environmental contaminants pose, the administrative requirements are much stricter and the available test systems far more advanced than they were, especially for agricultural chemicals. Despite this, as Martin (2021) points out, there are still many holes and we have not succeeded in eliminating the threats from persistent organic substances despite our discoveries and improved scientific knowledge. Also Farrington (2021) stresses that our societies keep adding new chemicals to the ever longer list of environmental contaminants. It might be that the greater risks for the future may not be caused by individual chemicals in high concentrations but come from the collective synergetic effects of a huge number of substances, each of them in concentrations well below toxic threshold values. Such effects will be very difficult to identify the cause of, when we detect them in nature, and almost impossible to find in pre-use screening. Even when such causes are identified, legislating to prevent them will be a nightmare. Farrington (2021) also underlines that we, including environmental scientists, for far too long have neglected the accumulation of plastics in the environment. They don't bioaccumulate the way traditional POPs do, but pose a grave long-term threat anyway.

\section{REFERENCES}

Borg, K. 1966. Mercury poisoning in Swedish wildlife. Journal of Applied Ecology 3: 171-172.

Carson, R. 1962. Silent Spring. USA: Houghton Mifflin.

Farrington, J. 2021. Reflecting on three influential Ambio articles impacting environmental biogeochemistry research and knowledge. 50th Anniversary Collection: Environmental contaminants. Ambio, Vol. 50. https://doi.org/10.1007/s13280-02001416-7.
Fimreite, N. 1970. Mercury contamination of Canadian fish and fisheating birds' Background papers for the Great Lakes environmental conference. Toronto: Ontario.

Goldberg, E. 1975. Synthetic organohalides in the sea. Proceedings of the Royal Society London B 189: 277-289.

Grandjean, P., P. Weihe, R.F. White, F. Debes, S. Araki, K. Yokoyama, K. Murata, N. Sorensen, et al. 1997. Cognitive deficit in 7-year-old children with prenatal exposure to methylmercury. Neurotoxicology and Teratology 19: 417-428.

Hachiya, N. 2006. The history and the present of Minamata diseaseEntering the second half a century. Japan Medical Association Journal 49: 112-118.

Jensen, S. 1972. The PCB story. Ambio 1: 123-131.

Jensen, S. 2021. Afterthoughts from an environmental pollution discovery: Interview with Sören Jensen. 50th Anniversary Collection: Environmental contaminants. Ambio, Vol. 50. https://doi.org/10.1007/s13280-020-01453-2.

Jensen, S., and A. Jernelöv. 1967. Biological formation of methyl mercury in sediments. Nordforsk 14: 3-6.

Jensen, S., and A. Jernelöv. 1969. Biological methylation of mercury in biological organisms. Nature 223: 753-754.

Johnels, A.G., T. Westermark, W. Berg, P.I. Persson, and B. Sjöstrand. 1967. Pike (Esox lucius L.) and some other aquatic organisms in Sweden as indicators of mercury contamination in the environment. Oikos 18: 323-333.

Landner, L. 1971. Biochemical model for the biological methylation of mercury suggested from methylation studies in vivo with Neurospora crassa. Nature 230: 452-454.

Martin, J.W. 2021. Revisiting old lessons from classic literature on persistent global pollutants. 50th Anniversary Collection: Environmental contaminants. Ambio, Vol. 50. https://doi.org/10. 1007/s13280-020-01413-w.

Mergler, D. 2021. Ecosystem approaches to mercury and human health: A way toward the future. 50th Anniversary Collection: Environmental contaminants. Ambio, Vol. 50. https://doi.org/10. 1007/s13280-020-01455-0.

Mergler, D., H. Anderson, L.H.M. Chan, K. Mahaffey, M. Murray, M. Sakamoto, and A. Stern. 2007. Methylmercury exposure and health effects in humans: A worldwide concern. Ambio 36: 3-11.

Myers, G.J., P.W. Davidson, C. Cox, C.F. Shamlaye, D. Palumbo, E. Cernichiari, J. Sloane-Reeves, G.E. Wilding, et al. 2003. Prenatal methylmercury exposure from ocean fish consumption in the Seychelles child development study". The Lancet 361: $1686-1692$.

Rappe, C. 1974. Chemical behavior of Pesticides. In Ecological Problems of the circumpolar area, 29-32 + 37. Norrbottens Museum, Luleå, Sweden.

Wania, F. 2021. The unlikely fate of a term paper. 50th Anniversary Collection: Environmental contaminants. Ambio, Vol. 50. https://doi.org/10.1007/s13280-020-01456-z.

Wania, F., and D. Mackay. 1993. Global fractionation and cold condensation of low volatility organochlorine compounds in polar regions. Ambio 22: 10-18.

Westöö, G., and K. Norén. 1967. Kvicksilver och metylkvicksilver i fisk. Vår Föda 10.

Wood, J.M., F.S. Kennedy, and C.G. Rosén. 1968. Synthesis of methyl mercury compounds by extracts of a methanogenic bacterium. Nature 220: 173-174.

Publisher's Note Springer Nature remains neutral with regard to jurisdictional claims in published maps and institutional affiliations.

\section{Arne Jernelöv $(\square)$}

Address: Stockholm, Sweden.

e-mail: arne.jernelov@gmail.com 


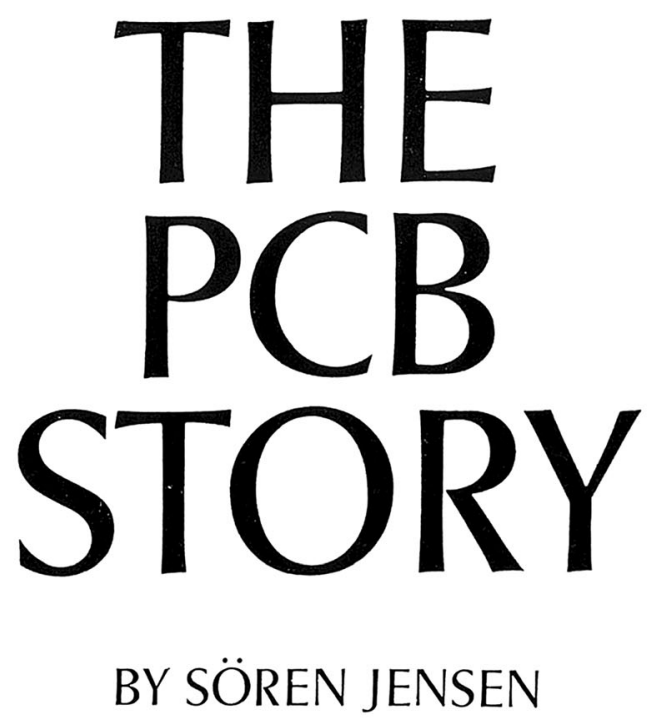

The accumulation of $P C B$ in nature and thus in the food chains was unknown to scientists until 1966, although the substance had been used industrially since 1929. It was the Swedish chemist Sören Jensen who, when analyzing DDT accumulations

in nature, accidentally found enormous quantities of unknown substances that were later on identified as $P C B$ compounds. $P C B$ constitutes perhaps the most stable group of organic substances in existence. It poses, therefore, a severe threat to life-forms.

In Sweden this discovery has led to a law prohibiting the use, import, manufacture and sale of PCB without permission from the authorities.

In this article Sören Jensen gives, for the first time, the complete story of his discovery of the substances. He also presents test results which show the PCB levels in blood samples from PCB-contaminated Japanese and other persons. The article can be read as a detective story with a moral. It can also be considered as an example of the kind of unpleasant discoveries we can expect unless environmental controls are applied to all dangerous substances before they are used extensively, before they can contaminate the Earth.

PCB pollution in nature was discovered at a rather late date, but considering the circumstances, it is perhaps surprising that it was discovered at all.

While the contamination of nature by $\mathrm{PCB}$ was not detected until 1966, the accumulation of DDT in nature was first recognized in the 1950's. During the late 1950's and early 1960's biologists and chemists became increasingly aware of DDT and mercury pollution.

The presence of these two substances in the food chains was discovered before the presence of other contaminants such as PCB was revealed, largely because of the obvious connection in time and space between the use of DDT and mercury and the negative effects caused by them.

When farmers used mercury-treated seed, pheasants that lived in the fields and ate the seed died. When DDT was sprayed on plants to kill noxious insects, the birds living on the insects disappeared (1). In these cases, where there was rather clear evidence of cause-and-effect in situations that were relatively easy to observe, biologists could turn to analytical chemists for final proof of their hypotheses (2). 


\section{Global Fractionation and Cold Condensation of Low Volatility Organochlorine Compounds in Polar Regions}

Organochlorine chemicals, including chlorinated pesticides and polychlorobiphenyls, are found at appreciable concentrations in the polar regions, presumably as a result of longrange atmospheric transport. Concentration data in arctic and antarctic air, snow, atmospheric deposition, fish and seals, measured by various investigators, are compiled and interpreted to determine latitudinal and temporal trends. It is suggested that the often surprisingly high concentrations are explained in part by the temperature-dependent partitioning of these low volatility compounds. A process of global fractionation may be occurring in which organic compounds become latitudinally fractionated, "condensing" at different ambient temperatures dependent on their volatility. We suggest that compounds with vapor pressures in a certain low range may preferentially accumulate in polar regions. Possible adverse effects of these potentially toxic compounds on the indigenous population and on the arctic ecosystem are discussed. It is concluded that there is a need to control or even ban certain chemicals which have a tendency to fractionate into the polar ecosystems.

\section{INTRODUCTION}

For many years the polar regions were viewed as being too remote to be subject to any substantial chemical contamination from human activities. However, as was reviewed in issue No.1, 1989 of AMBIO, these regions can no longer be considered pristine, since they experience regular intrusions of polluted air masses known as "arctic haze". Research efforts in the late 1970 s and early 1980s have greatly increased our understanding of arctic pollution by aerosols as documented for example in the proceedings of the Arctic Air Chemistry Symposia and the results of the Arctic Gas and Aerosol Sampling Project $(1,2)$. Another pollution problem has recently attracted increasing attention, namely the occurrence of surprisingly high concentrations of toxic organic compounds in the polar environment.

Although early measurements in both the Arctic $(3,4)$ and Antarctic (5) revealed the ubiquitous distribution of these chemicals, the primary aim of these studies was to establish background concentrations in fairly pristine areas. The occurrence of DDT or PCB residues in polar wildlife was considered only a minor problem meriting only brief accounts in two 1986 texts summarizing the state of knowledge in arctic air pollution $(6,7)$.
It has been realized recently that the concentrations found are surprisingly high, and continue to remain high, despite the ban on many of these substances in most of the industrialized countries of the Northern Hemisphere. The levels found in arctic wildlife tissues have been considered high enough to trigger concerns about the impact on the indigenous population of the Canadian North, which is heavily dependent on local foods as a source of diet, and may be exposed to contaminant levels sufficient to cause adverse health effects (8).

In this review we attempt to summarize and analyze the state of knowledge in this area and point out certain features of chemical behavior in cold environments. It is first useful to compile concentration data measured by different investigators in various environmental compartments. We then analyze these data and formulate hypotheses concerning chemical behavior in cold polar regions.

\section{ORGANOCHLORINE LEVELS IN COLD ENVIRONMENTS}

\section{Air Measurements}

Since the atmosphere is a major pathway of chemicals to the polar regions considerable effort has been devoted to measuring toxic organic compounds in the arctic atmosphere. During the early 1980s, the Norwegian Institute for Air Research measured organochlorine (OC) compounds at several stations in the European Arctic (9-11). Measurements have since been made in the Canadian Arctic (12-17) and during several cruises in the Bering and Chukchi Sea (18) and the Southern Ocean (19).

The chlorinated hydrocarbons detected include DDT and its metabolites DDD and DDE (referred to here as DDTs), pesticides such as technical chlordane, heptachlor, hexachlorocyclohexanes ( $\mathrm{HCHs}$ ), dieldrin, and polychlorinated camphenes (PCCs or toxaphene); industrial chemicals and combustion by-products such as polychlorinated biphenyls (PCBs) and chlorobenzenes; and finally the notorious polychlorinated dibenzo-p-dioxins and -furans. Other OC compounds may have evaded identification. Table 1 gives a compilation of selected $\mathrm{OC}$ concentration levels in air obtained during these measurements (modified from reference 16 , extended with data from $11,14,17,18)$. For comparison, some recent measurements in temperate latitudes are included (20-22) as are measurements from Antarctica (19).

The data suggest rather homogeneous concentrations of the OCs in air throughout the Arctic. Absolute concentrations and 


\section{Methylmercury Exposure and Health Effects in Humans: A Worldwide Concern}

\begin{abstract}
The paper builds on existing literature, highlighting current understanding and identifying unresolved issues about $\mathrm{MeHg}$ exposure, health effects, and risk assessment, and concludes with a consensus statement Methylmercury is a potent toxin, bioaccumulated and concentrated through the aquatic food chain, placing at risk people, throughout the globe and across the socioeconomic spectrum, who consume predatory fish or for whom fish is a dietary mainstay. Methylmercury developmental neurotoxicity has constituted the basis for risk assessments and public health policies. Despite gaps in our knowledge on new bioindicators of exposure, factors that influence $\mathrm{MeHg}$ uptake and toxicity, toxicokinetics, neurologic and cardiovascular effects in adult populations, and the nutritional benefits and risks from the large number of marine and freshwater fish and fish-eating species, the panel concluded that to preserve human health, all efforts need to be made to reduce and eliminate sources of exposure.
\end{abstract}

\section{INTRODUCTION}

The Panel on Health Risks and Toxicological Effects of Methylmercury received the mandate to describe and synthesize current scientific knowledge on methylmercury $(\mathrm{MeHg})$ exposure and its effects in humans and to identify research gaps. The present paper is not intended to be a comprehensive review and presentation of all the literature on $\mathrm{MeHg}$ exposure and effects in humans but builds on earlier literature, other reviews, and more recent literature in highlighting the current understanding in the field and what we consider to be remaining unresolved issues. Humans are exposed to different forms of mercury $(\mathrm{Hg})$, and potential health risks from forms other than $\mathrm{MeHg}$ can occur, including mercury vapor from dental amalgams, as well as from occupational exposures (e.g., dental offices, chloralkali plants, fluorescent lamp factories, mercury mining) and from artesanal and small-scale gold and silver mining operations (15), the present document does not cover these exposures, because the pathways of exposure and effects differ from those for $\mathrm{MeHg}$. Here, we examine issues of $\mathrm{MeHg}$ exposure, studies on its health effects and major risk assessments, and conclude with our consensus statement.

\section{MeHg Exposure}

Sources of exposure. Methylmercury contamination poses a particular challenge to public health because this toxicant is mainly contained in fish, a highly nutritious food, with known benefits for human health. Moreover, fish are culturally vital for many communities and constitute an important global commodity. Although we often refer to "fish" in a generic way, all fish do not have similar amounts of mercury. As a result of bioaccumulation of $\mathrm{MeHg}$ through multiple levels of the aquatic food web, higher tropic-level pelagic fish can be contaminated with $\mathrm{MeHg}$ at concentrations in excess of 1 part per million (ppm). The concentrations of total $\mathrm{Hg}$ vary widely across fish and shellfish species, with the mean values differing by as much as 100-fold (6). Methylmercury is bound to proteins, as well as to free amino acids, that are components of muscle tissues, and are not removed by any cooking or cleaning processes that do not destroy muscle tissues.

Although in general, $\mathrm{MeHg}$ accumulates in fish through the food chain, consumption of farmed fish can also lead to $\mathrm{MeHg}$ exposures, in part, because of the presence of $\mathrm{MeHg}$ in feed (7). Some studies have shown no significant difference in $\mathrm{MeHg}$ levels in farmed $v$ s. wild salmon, although concentrations in both cases are relatively low $(8,9)$. Although fish and shellfish are the predominant sources of $\mathrm{MeHg}$ in the diets of humans and wildlife, a few reports of other sources exist. Rice cultivated in areas contaminated with mercury can contain relatively high levels of $\mathrm{MeHg}(10)$. Methylmercury has also been reported in organ meats of terrestrial animals (11), as well as in chicken and pork, probably as a result of the use of fish meal as livestock feed (12). Some communities also have higher $\mathrm{MeHg}$ exposure because of the consumption of fish-eating marine mammals $(13,14)$.

Profiles of exposure. Although most reports on $\mathrm{MeHg}$ exposure focused on specific populations generally assumed to have high levels of fish consumption, estimates of general populations exposure exist for the United States $(15,16)$, Germany (17), and Japan (18) [summarized in Pirrone and Mahaffey (19)]. For populations that are not selected on the basis of high fish consumption, mean hair $\mathrm{Hg}$ levels generally range from $>0.1 \mu \mathrm{g} \mathrm{g}^{-1}$ to $<1.0 \mu \mathrm{g} \mathrm{g}^{-1}(20-25)$. The mean blood $\mathrm{Hg}$ for such populations is generally in the range of $<1.0 \mu \mathrm{g} \mathrm{L}^{-1}$ to $<5.0 \mu \mathrm{g} \mathrm{L}^{-1}$, although, worldwide there are fewer data on $\mathrm{MeHg}$ exposure based on blood than on hair. In the United States nationally, about $5-10 \%$ of the population of women of childbearing age have hair levels exceeding $1.0 \mu \mathrm{g} \mathrm{g}^{-1}$ (16) and blood levels exceeding $5 \mu \mathrm{g} \mathrm{L}^{-1}$ (26). In Japan, where more fish is consumed, $73.7 \%$ of women of this age have hair levels above $1.0 \mu \mathrm{g} \mathrm{g}^{-1}$ and $1.7 \%$ above $5 \mu \mathrm{g} \mathrm{g}^{-1}$ (18). In Germany, the 1998 geometric mean blood level was $0.58 \mu \mathrm{g} \mathrm{L}^{-1}(17)$.

High levels of $\mathrm{Hg}$ exposure were identified in numerous fisheating populations throughout the world [for reviews see: Pirrone and Mahaffey (19)]. Many of these live near oceans, major lakes and rivers, or hydroelectric dams, and are often dependent on local catch, with fish an integral part of their cultural traditions. In the sea islands of the Faroes and Seychelles, median mothers' hair $\mathrm{Hg}$ concentrations were 4.5 $\mu \mathrm{g} \mathrm{g}^{-1}$ [with $27 \%$ above $10 \mu \mathrm{g} \mathrm{g}^{-1}$ (27)] and $5.8 \mu \mathrm{g} \mathrm{g}^{-1}$ (28), respectively. In the river basins of the Amazon, where a large number of studies was carried out on populations for whom freshwater fish is a dietary mainstay, median hair $\mathrm{Hg}$ levels typically range between $5 \mu \mathrm{g} \mathrm{g}^{-1}$ and $15 \mu \mathrm{g} \mathrm{g}^{-1}$ (29-34).

Despite the importance of local catch, fish is also a global commodity and market fish, such as shark, tuna, and swordfish, or canned white tuna (35), consumed by persons living far away from the source can likewise have high levels of $\mathrm{MeHg}$. In the United States, individuals with high blood $\mathrm{Hg}$ concentrations were reported among affluent urbanites who ate large quantities 